\title{
Vulnerabilidade na saúde do adolescente: questões contemporâneas
}

\author{
Vulnerability in adolescent health: contemporary issues
}

Marta Angélica Iossi Silva ${ }^{1}$

Flávia Carvalho Malta de Mello ${ }^{1}$

Débora Falleiros de Mello ${ }^{1}$

Maria das Graças Carvalho Ferriani ${ }^{1}$

Julliane Messias Cordeiro Sampaio ${ }^{1}$

Wanderlei Abadio de Oliveira ${ }^{1}$

${ }^{1}$ Escola de Enfermagem de Ribeirão Preto,

Universidade de São Paulo. Av. Bandeirantes 3900,

Monte Alegre. 14.040-902 Ribeirão Preto SP Brasil. maiossi@eerp.usp.br

\begin{abstract}
The objective of this exploratory study with a qualitative approach was to analyze how adolescents perceive reality in terms of vulnerability in respect to health. A total of 17 semistructured interviews were staged with adolescents from two elementary-middle $(k-8)$ schools in a city in the interior of São Paulo, Brazil. Content analysis was used to interpret the data, from which three thematic nuclei emerged. The results revealed that the adolescents understand the complex interaction between individual predisposition and health vulnerability, as well as the issues related to social structure, which contributes to strengthening the concept of vulnerability based on individual, social and programmatic logic. It was established that public policies, prevention and care provided during adolescence should not be guided by a single reference point, but instead by the plurality of the adolescent individuals concerning vulnerability in their dimensions, which should be acknowledged in order to break with the idea of the universality of the process of becoming an adolescent.
\end{abstract}

Key words Health vulnerability, Adolescent health, Risk indicator, Violence
Resumo Este estudo exploratório de natureza qualitativa objetivou analisar como adolescentes percebem a realidade em termos da vulnerabilidade na saúde. Foram realizadas 17 entrevistas semiestruturadas com adolescentes de duas escolas de educação fundamental de um município do interior do estado de São Paulo. A interpretação dos dados, orientada pela análise de conteúdo, fez emergir três núcleos temáticos. Os resultados indicaram que os adolescentes compreendem a complexa interação entre a predisposição individual à vulnerabilidade para a saúde, bem como as questões relacionadas à estrutura social, o que contribui para o fortalecendo da concepção de vulnerabilidade a partir das lógicas individual, social e programática. Identificou-se que as políticas públicas, a prevenção e a assistência na adolescência não devem ser orientadas por um único referencial, mas sim pelo reconhecimento da pluralidade do ser adolescente quanto à vulnerabilidade em suas dimensões, rompendo, dessa forma, com a ideia de universalidade do processo de adolescer. Palavras-chave Vulnerabilidade em saúde, Saúde do adolescente, Indicador de risco, Violência 


\section{Introdução}

Conhecer e refletir sobre as percepções dos adolescentes acerca do seu contexto sociocomunitário impõe-se como desafio e exercício para compreender e transformar as práticas de saúde, em especial as de enfermagem, validando a correção ética e compromissada das ações, buscando observar, por meio e para além de suas interfaces, os seus significados, propostas de intervenção e prevenção. Esses processos exigem novos conhecimentos e uma ação proativa, capazes de gerar uma consciência coletiva e um compromisso frente aos problemas de desigualdade, exclusão, discriminação e situações de vulnerabilidade aos quais muitos adolescentes estão expostos.

O Estatuto da Criança e do Adolescente circunscreve a adolescência como período de vida que vai dos 12 aos 18 anos de idade, já a Organização Mundial da Saúde a delimita como a segunda década de vida, 10 aos 19 anos, fronteira cronológica adotada neste estudo ${ }^{1}$.

Entendemos que a concepção do ser adolescente deve estar pautada em uma visão sistêmica e construtivista do processo de adolescer, onde o sujeito desse processo seja visto dentro de suas singularidades, bem como em suas interações com o seu contexto familiar e social, em um dado momento histórico e cultural.

A proposta de atenção integral à saúde dos adolescentes é intervir nesse processo por meio de ações que deem escuta, satisfaçam suas necessidades e permitam o desenvolvimento de competências e habilidades, tornando-os parte de redes sociais alicerçadas em perspectivas de enfrentamento e de minimização da vulnerabilidade.

A noção de vulnerabilidade procura particularizar as diferentes situações dos sujeitos em três planos analíticos, ou seja, a vulnerabilidade individual, social e programática. A vulnerabilidade individual está relacionada aos aspectos que dependem diretamente das ações individuais, configurando o comportamento e as atitudes do sujeito, a partir de um determinado grau de consciência que ele manifesta. Por seu turno, a vulnerabilidade social se caracterizada pelo contexto econômico, político e social, que dizem respeito à estrutura disponível de acesso a informações, financiamentos, serviços, bens culturais, liberdade de expressão, entre outros, e a vulnerabilidade programática se refere às ações comandadas pelo poder público, iniciativa privada e agências da sociedade civil, que visam ao enfrentamento das situações que causam vulnerabilidade, proposição de ações e destinação de recursos com esta finalidade ${ }^{2-4}$.
A fundamentação desses três componentes analíticos interdependentes aponta para a pretensão conceitual da vulnerabilidade, ou seja, buscar uma "síntese", em contraste ao caráter eminentemente analítico do conceito de risco, exigindo, portanto, olhares para múltiplos planos e, em particular, para estruturas sociais vulnerabilizantes ou condicionamentos de vulnerabilidades, colocando-se como convite à renovação das práticas de saúde, como sociais e históricas, envolvendo diferentes setores da sociedade ${ }^{2-4}$.

A literatura apresenta resultados sobre as relações entre as condições de vulnerabilidade e a saúde de adolescentes, evidenciando a existência de estudos nessa direção, mas ainda é possível identificar que as investigações, em geral, estão focadas em situações específicas como as práticas sexuais e a gravidez na adolescência, a exemplo dos estudos de Ferreira et al. ${ }^{5}$ e de Cabral e Oliveira $^{6}$, ou a fatores de risco social e comportamental ${ }^{2,7}$.

Destarte, há uma prevalência de investigações sobre HIV, uso de preservativos, iniciação sexual, relações de gênero, classe e raça, comportamentos de proteção, formação de multiplicadores para a prevenção de doenças sexualmente transmissíveis, desafios clínicos, abuso sexual, cuidados e direitos em saúde sexual e reprodutiva e sobre métodos contraceptivos, bem como sobre a saúde pública nestes contextos ${ }^{8-12}$. Especificamente, no que se refere à gravidez na adolescência, os estudos privilegiam o olhar dos profissionais de saúde sobre o fenômeno, análises sobre sua distribuição e características em determinados territórios, e as tendências da produção científica em determinadas áreas, como a psicologia e a enfermagem ${ }^{5-6,13}$.

Outros estudos exploram temas relacionados às condições específicas de vulnerabilidade, como o acolhimento institucional, a condição de rua e as propostas socioeducativas, a pobreza, a mortalidade e acidentes não fatais ${ }^{14,15}$. Apreciações sobre o uso de álcool e outras drogas caracterizam serviços de atenção aos adolescentes, bem como refletir sobre o abuso dessas substâncias neste momento do desenvolvimento humano e compreender a representação do consumo de bebidas alcoólicas para adolescentes e os fatores de risco relacionados a esta prática ${ }^{16}$. A literatura valoriza interfaces entre as áreas para o cuidado ao mesmo tempo em que privilegiam as perspectivas da promoção da saúde.

As investigações também priorizam a identificação de estratégias para a diminuição das situações de vulnerabilidade social entre adolescentes ${ }^{17}$ 
e a construção de reflexões sobre o conceito de vulnerabilidade e o entendimento de sua complexidade e dimensões, assim como as potencialidades de sua compreensão no campo da saúde coletiva para a transformação das práticas na área ${ }^{18,19}$. As questões relacionadas às dinâmicas sociais da vida de adolescentes igualmente é valorizada, principalmente no que concerne à violência e às relações cotidianas e sociais ${ }^{20}$. Alguns estudos, ainda, caracterizam políticas públicas voltadas para os adolescentes e possuem escopos intersetoriais e perspectivas de reflexão documental ${ }^{21}$.

Desta forma, problematiza-se a relevância de estudos que oportunizem a compreensão de como os adolescentes percebem a realidade concreta em que estão inseridos em termos da vulnerabilidade para a saúde, uma vez que se torna imprescindível uma escuta sensível a eles, ao seu pensar, às suas percepções e necessidades, a fim de se estabelecer possibilidades reais e contextuais do e para o mundo adolescente, sobretudo no que diz respeito às políticas e ações em saúde.

Neste sentido, objetivou-se analisar como adolescentes percebem a realidade em termos da vulnerabilidade da sua saúde. Essa análise pode subsidiar respostas às questões de pesquisa elencadas previamente: os adolescentes se reconhecem como um grupo vulnerável? A que tipo de vulnerabilidade eles estão expostos, considerando o contexto de inserção?

\section{Métodos}

Tratou-se de um estudo de natureza qualitati$\mathrm{va}^{22}$, realizado em 2009 , cujo pano de fundo foi a compreensão de que os adolescentes são sujeitos únicos e plurais que possuem uma história e uma consciência crítica, com ações permeadas de intenção e significado capazes de revelar sua visão de mundo e suas percepções. Neste sentido, compreende-se que a abordagem qualitativa, aqui entendida como aquela que permite incorporar significados e a intencionalidade como inerentes aos atos, às relações e às estruturas sociais e como práticas interpretativas que contemplam os sentidos que os sujeitos atribuem aos fenômenos ${ }^{22,23}$, melhor responde aos objetivos deste estudo.

O campo de pesquisa foram duas escolas municipais de ensino fundamental, localizadas em bairros periféricos de um município do interior do estado de São Paulo. As escolas foram selecionadas por conveniência, uma vez que eram espaços de desenvolvimento de atividades e grupos de educação em saúde com alunos do ensino fundamental (a partir do $7^{\circ}$ ano) que integravam um projeto de extensão dos pesquisadores e possuíam vínculos efetivados com uma universidade pública. Ambas as escolas agregam adolescentes de classes populares, oriundos de famílias de baixa renda, muitas com limitadas condições socioeconômicas. Localizam-se em bairros periféricos caracterizados pela escassez de equipamentos e investimentos sociais, como redes de apoio e programas, fatores que vêm mantendo os níveis de desigualdade econômica, cultural e social na região.

Participaram do estudo 17 adolescentes, alunos dos $7^{\circ}, 8^{\circ}$ e $9^{\circ}$ ano do ensino fundamental e se utilizou como método de coleta de dados entrevistas semiestruturadas. Os alunos foram selecionados após participarem dos grupos de educação em saúde propostos pelo projeto de extensão mencionado, considerando-se aqueles que manifestaram interesse em aderir ao estudo. $\mathrm{O}$ grupo de sujeitos foi atingido considerando-se a representatividade da amostra por meio da técnica de saturação ${ }^{24}$. Na escola A foram realizadas 9 entrevistas e, na escola B, 8 .

O contato com os adolescentes se realizou fora da sala de aula e no primeiro momento foi explicitado a eles os objetivos do estudo, seguindo-se a coleta de dados, após consentirem, juntamente com seus responsáveis, por meio dos termos de assentimento e consentimento livre e esclarecido. O roteiro para coleta de dados possuía 2 dimensões, permitindo investigações sobre: o que é estar vulnerável e a que tipo de problema ou situação de vulnerabilidade estavam sujeitos ou enfrentavam.

Em termos de tratamento dos depoimentos, utilizou-se o método de análise de conteúdo em sua modalidade temática ${ }^{22}$. Neste sentido, a trajetória analítico-interpretativa percorreu os seguintes passos: (i) contato exaustivo com o material (leitura flutuante); (ii) apreensão das particularidades do material gerado pela pesquisa original, identificação e recorte temático dos depoimentos acerca das questões investigadas e relacionadas à vulnerabilidade na adolescência; (iii) organização do material, considerando critérios de exaustividade, representatividade, homogeneidade e pertinência (constituição do corpus); (iv) determinação de palavras-chaves ou frases, recortes, modalidade de codificação e conceitos teóricos a serem analisados no estudo; (vi) exploração do material, visando a alcançar os núcleos temáticos e, na sequência, correlacionar os núcleos de sentidos de cada fala; e (vii) elaboração da síntese interpretativa ${ }^{22,23}$. 
Em geral, os adolescentes manifestaram questões que se mostram relevantes quando abordamos a vulnerabilidade em relação à saúde, como: a exposição a riscos, a falta de conhecimento, o pouco acesso a serviços de saúde, a falta de boas escolas, a violência, a criminalidade, as precárias condições econômicas das comunidades, o sexo inseguro, a falta de autocuidado e a carência por ações governamentais. Estas questões se depreenderam do conjunto das falas dos adolescentes e se configuraram como núcleos de sentidos que permitiram a construção de três temáticas analíticas que serão exploradas a seguir, quais sejam: Déficits que vulnerabilizam a saúde dos adolescentes; Pro que der e vier: riscos; e Violência e criminalidade: fatores que comprometem a saúde.

Para garantir o caráter sigiloso das informações e dos sujeitos, na transcrição dos depoimentos, as entrevistas foram codificadas por letras onde "E1A" refere-se à entrevista número um da escola A; e "E1B" refere-se à entrevista número um da escola B; e assim sucessivamente.

O projeto de pesquisa foi avaliado e aprovado pelo Comitê de Ética em Pesquisa da Escola de Enfermagem de Ribeirão Preto da Universidade de São Paulo. Em todas as fases do estudo se seguiu as orientações e recomendações da Resolução no ${ }^{\circ}$ 196/96 ${ }^{25}$ do Conselho Nacional de Saúde e os adolescentes somente participaram após seu assentimento e o consentimento de seus responsáveis legais, como mencionado.

\section{Resultados e discussão}

\section{Déficits que vulnerabilizam a saúde dos adolescentes}

O material empírico analisado revelou que os diversos tipos de "faltas" são a tônica dos discursos e da compreensão dos adolescentes sobre a vulnerabilidade. Aspecto de valor capital para a apreciação sobre vulnerabilidade a partir de suas três dimensões: individual, social e programática.

[...] mais se a gente não tem uma boa escola ou um posto de saúde que atenda a gente direito a gente também fica em mais perigo... Vulnerável... (E2A).

Muitos adolescentes vivem numa condição completamente precária, [...] ninguém, nem a casa dele tem condições (E4B).

[...] tem também a gravidez, na adolescência, muitos jovens que não têm prevenido, acaba ocorrendo isso. E a AIDS, porque as pessoas fazem e não se cuidam. Acaba acontecendo isso (E5B).
Os adolescentes apontaram a falta de conhecimento em relação à vida sexual saudável, de responsabilidade, do autocuidado (dimensão individual), de condições materiais de vida, de comunidades seguras (dimensão social), de ações governamentais efetivas para a emancipação da vida, de educação e suas instituições e de melhor acesso aos serviços de saúde (dimensão programática).

As falas expostas traduzem o pensamento de que a vulnerabilidade é tema complexo e a necessidade de uma abordagem integral capaz de considerar os valores, as crenças, os conhecimentos, os fatores contextuais, históricos e culturais das comunidades, bem como os recursos sociais necessários para o desenvolvimento humano saudável dos adolescentes. A educação é percebida como faceta que emancipa e rompe com ciclos de pobreza e desigualdade social que tendem a vulnerabilizar a condição de saúde dos adolescentes $^{6,8,15,26}$.

Os adolescentes, sobremaneira, também apontaram a falta de conhecimento e autocuidado quando diante das questões relacionadas à vida sexual. Eles indicam que as doenças sexualmente transmissíveis, como o HIV/AIDS, e a gravidez na adolescência, são decorrentes de fatores de vulnerabilidade em função da não prevenção ou da imaturidade.

[...] as meninas estão enfrentando muita gravidez, na adolescência, porque não fazem [sexo] com segurança (E12A).

Ah, falta de camisinha, que às vezes os jovens faz isso [sexo sem camisinha] por uma brincadeira assim, e eu acho que pra fazer isso eles tinham que ter mais responsabilidade (E7B).

É na discussão sobre o HIV, especificamente, que estudos se referem demasiadamente às faltas. Em um estudo exploratório-descritivo de abordagem quantitativa, que objetivou analisar comparativamente a vulnerabilidade ao HIV/ AIDS de adolescentes, por exemplo, Anjos et al. ${ }^{8}$ em uma amostra de 207 adolescentes, identificaram déficits de conhecimento sobre o processo de transmissão do HIV e até mesmo sobre as práticas sexuais seguras.

Salienta-se que a sexualidade é uma dimensão fundamental para o desenvolvimento humano, e que envolve práticas e desejos relacionados à satisfação, à afetividade, ao prazer, aos sentimentos, ao exercício da liberdade e à saúde. Dimensão histórica e cultural do desenvolvimento que na contemporaneidade vive um processo de rompimento de limites das possibilidades de vivência, tabus, mitos, preconceitos e interdições. 
Assim, as “aventuras” e as "brincadeiras” dos adolescentes contestam essas ordens vigentes, dentro do próprio movimento do adolescer de se afirmar e romper com paradigmas ${ }^{9}$.

Para os adolescentes participantes do estudo, a experiência da sexualidade traduz as potencialidades do próprio existir conquanto seja colocada no campo das descobertas, experimentações e vivência de uma liberdade, além de servir de aporte para a construção da capacidade de tomada de decisões, de escolhas, de responsabilidades, exercida de forma singular e com a urgência própria dos adolescentes.

A gravidez na adolescência, por sua vez, é derivada da "falta de camisinha" ou da "falta de responsabilidade", sumariamente das condições de vulnerabilidade. Em geral, os estudos consideram essa gravidez como situação de vulnerabilidade e como elemento determinante na reprodução do ciclo de pobreza das populações, ao colocar impedimentos na continuidade de estudos e no acesso ao mercado de trabalho das adolescentes ${ }^{6,13,27}$.

Destaca-se que a gravidez em si não pode ser classificada como condição de vulnerabilidade à saúde, mas na adolescência ela compromete outras dimensões da vida das adolescentes, como a educação, o que indiretamente vulnerabiliza a saúde delas. Este entendimento é de que são as decorrências da gravidez que vulnerabilizam a saúde, pois é iniciada no sexo inseguro, na falta de autocuidado entre outros aspectos.

Outros déficits relacionados à vulnerabilidade na saúde dos adolescentes mencionados estão associados às relações econômicas, políticas, culturais que configuram a estrutura social. Os condicionantes estruturais colocam ou aumentam a vulnerabilidade das pessoas ou grupos, e que a melhoria da situação socioeconômica das famílias, e a garantia de políticas e serviços sociais, diferenciados e ajustados a cada contexto, são mediações para diminuir esta vulnerabilidade ${ }^{4}$.

Muitos pais e colegas daqui não têm condição, eu acho que os políticos deveriam fazer mais, pensar mais no povo e em nós [...] eles falam muito e chegando lá [no governo] muda totalmente. Pode ser o máximo de esquerda, que chegando lá você vira direita [...]. Tem alguma ajuda, algumas coisas para os jovens, mas a gente não precisa só disso, precisa de muito mais (E4B).

Sabe pra ficar mais protegido a gente precisa de mais apoio, mais condições, mas o governo não vê isso (E8B).

A compreensão de processos de vida que terminam vulnerabilizando a saúde dos adolescen- tes é análoga à apreensão de alguns destes, de que a desigualdade social reflete a incapacidade brasileira em incorporar sua população à cidadania, à garantia de direitos políticos, civis e sociais, já que estamos longe de incorpora-la nos direitos sociais ${ }^{28}$.

O padrão da pobreza no Brasil tem se alterado, observando-se uma redução da sua incidência, o que se deve mais a um efeito de mudanças entre gerações do que alterações específicas nos períodos. Em relação à composição da pobreza, o processo mais acelerado de redução é do componente crônico. Em contrapartida, o componente transitório apresenta uma tendência de aumento entre a população, especialmente jovem ${ }^{28}$.

Estudos apontam a pressão e a angústia do jovem na atualidade frente à impossibilidade de adquirir os bens e recursos materiais e sociais que almeja, de satisfazer os desejos criados pelo mercado e apresentados como necessidades de consumo, sendo que a população de baixa renda percebe essa necessidade com uma expansão no grau de vulnerabilidade e incerteza ${ }^{4,20,28,29}$. Ao mesmo tempo em que apontam para a perversa estrutura do sistema econômico vigente que contribui para que sucumbamos ao mal-estar generalizado da sociedade contemporânea que privilegia o individualismo narcíseo ${ }^{29}$.

Na percepção dos adolescentes, para aplacar as "faltas", os déficits, existentes em suas vidas e os fatores e situações que os vulnerabilizam em relação à saúde, são necessários enfrentamentos de ordem programática. Caberia aos governos e suas propostas políticas responderem a esse tipo de condição de vida, dinâmica engendrada e subsidiada por maiores investimentos, por exemplo, na área educacional.

[...] educação traz tudo, traz o emprego, que traz alimento, que traz o dinheiro, para comprar alimento, vai atualizando a mente, que vai vendo as coisas, que vai pensando na vida (E5A).

Os adolescentes assinalaram necessidades na área educacional. Suas vozes ecoam (premissas do protagonismo juvenil) quando se colocam como sujeitos participantes de políticas que lhes dizem respeito, a exemplo das demandas por uma escola e serviços de saúde de qualidade. Neste sentido, estudos apontam que propostas centradas na construção de espaços que propiciem acessibilidade e participação dos jovens, objetivando a ampliação, readequação na melhoria da educação e saúde, são chaves para o desenvolvimento do capital humano e social ${ }^{21,29}$.

Propala-se com essa concepção a ideia de centralidade da educação no processo de transfor- 
mação social e dos projetos de vida dos adolescentes. Ampliando a reflexão, o desenvolvimento dos adolescentes e a construção de modelos de saúde estariam vinculados à emancipação de si (dimensão individual), de suas famílias e das comunidades (dimensão social) e a processos societários (dimensão programática).

\section{Pro que der e vier: riscos}

Os adolescentes identificaram a vulnerabilidade à saúde como associada à noção de risco, acreditando que ser vulnerável é correr risco de "pegar alguma doença" ou "sofrer algum dano que traga problema para a sua saúde". Neste cenário, a menção ao perigo de se infectar com alguma doença sexualmente transmissível ou a gravidez é atribuída às práticas de sexo inseguro e integrada ao termo "risco".

Estar vulnerável é quando a gente corre o risco de pegar alguma coisa (E2B).

Acho que é quando os jovens não sabem fazer a coisa certa pra se proteger [...] é a gente se expor e correr o risco de sofrer alguma coisa ruim (E8B).

Estes fragmentos das narrativas estabelecem relações entre os conceitos de risco e vulnerabilidade à saúde, pois propiciam a emersão de estratégias de atuação na saúde já que são tratados pela lógica da perda ou do algo a ser evitado. Sabe-se que a lógica dos riscos, na área da saúde, costuma ser entendida inversa à lógica da vulnerabilidade, mas pode-se entender que o envolvimento em uma situação de risco está relacionado às dimensões individual e social da vulnerabilidade $e^{4,8,16}$. Este entendimento termina colocando o estilo de vida dos adolescentes e as características de suas comunidades em pauta, pois a vulnerabilidade para a saúde foi entendida pelos adolescentes como um acontecimento ou a iminência de algo relacionado a essas dimensões (individual e social).

No bojo desta discussão, a proposição de uma reflexão sobre o cuidado quando diante de situações de risco é contextualizada pelos adolescentes, indicando as relações já mencionadas anteriormente entre as situações e as condições de vida e o quanto estas os vulnerabilizam em relação à saúde.

Têm adolescentes que a saúde deles está muito ruim, porque eles também começam a fazer muitas coisas que prejudicam o corpo. [...] eles também fazem sexo, eles podem também pegar AIDS, podem pegar muitas doenças. (E3A).

[...] sobre as doenças sexuais da juventude, porque tem muita gente que não é prevenida, que não se cuida. Eu tive uma amiga na quinta série, ela tava grávida, hoje ela tem três filhos (E8B).

Os exemplos elencados indicam que o risco é algo presente nas relações dos adolescentes e se associa às próprias características do momento vivido. Há uma difusão da ideia de que "se está aí para o que der e vier" que marca os movimentos dos adolescentes em seus processos de contestação da ordem, estabelecimento de outros tipos de relações e na tentativa de romper com o ciclo reprodutivo da pobreza e da violação dos direitos que culminam na incidência dos riscos e da vulnerabilidade na saúde.

Para os adolescentes o risco pertence às dimensões individual e social, traduzindo as demandas por ações governamentais efetivas para a emancipação da vida, melhor educação e acesso a serviços de saúde (dimensão programática). Muitas vezes são as condições sociais que facilitam, contribuem ou dificultam o desenvolvimento saudavel dos adolescentes, conduzindoos às condutas de práticas delituosas ou de risco.

Consideramos neste debate, assim, que a abordagem privilegiada do conceito de vulnerabilidade em relação à saúde dos adolescentes supera os limites do conceito de risco biológico/ individual, contribuindo, neste aspecto, com a ampliação do conhecimento e a proposição de outras práticas profissionais nas diversas áreas voltadas para o público adolescente.

\section{Violência e criminalidade: fatores que comprometem a saúde}

A vulnerabilidade na saúde para os adolescentes também estava relacionada à exposição e/ ou ao envolvimento com a violência e a criminalidade no cotidiano, na família, nas instituições, a exemplo da escola e nas ruas. Essas facetas da sociedade contemporânea se erigiram em grave expressão da questão social a ser enfrentada pelas políticas públicas e pela sociedade civil. Especificamente, no que se refere à adolescência e à vulnerabilidade da saúde, situações como "uso drogas", "roubos", "prostituição" e "morte", por exemplo, são contextos do desenvolvimento dos adolescentes.

São estas as experiências que muitos relatam quando se referem aos seus territórios de existência. Neste sentido, o estudo identificou que práticas de violência são realidades comuns para os adolescentes, percebidas algumas vezes como reflexo da "falta de governantes" ou da "falta de condições (socioeconômicas)", como mencionado. 
Você vê todo dia nas notícias adolescentes morrendo, matando se envolvendo em crime, aqui mesmo éassim. (E6A).

É que agora eu moro em outro bairro, mas quando morava aqui, tinha muito roubo de adolescente. Falta dinheiro, eles fumam droga, dai eles precisam de dinheiro para fumar. (E2A).

Nos debates sobre vulnerabilidades contemporâneas e juventudes, é comum ressaltar-se a exposição a diversos tipos de violência ${ }^{2,14,16,18,30}$, considerando em particular a alta incidência de mortes por causas externas (homicídios e assassinatos) entre os jovens. Neste contexto, os adolescentes percebem, seja no seu cotidiano mais próximo ou não, a delinquência e a violência interpessoal como fatores que os vulnerabiliza frente à saúde. $\mathrm{O}$ adolescente na dinâmica da violência assume papéis antagônicos como agressor/vítima, incluído/excluído, entre outros.

As expressões da violência e da criminalidade relatadas permitem a contrução de saberes sobre os múltiplos sentidos que estes fenômenos assumem. São imagens globais, em que pesem o atentado direto à vida das pessoas e à manutenção de estilos de vida impostos pela ordem do capital (consumo). A ação do Estado, focalizada pelos adolescentes, parece estar menos alicerçada na lógica da repressão, mas não há ainda uma concepção de que o enfrentamento destas quesões perpassa o entendimento de suas complexidades e da dificuldade de seu equacionamento diante da estrutura social.

Institucionalmente, a escola é local que manifesta situações vivenciadas no âmbito social, logo nela também se delineiam as questões da violência e da criminalidade na sociedade contemporânea.

$\mathrm{Na}$ escola agora até os pequenos ameaçam bater, tirar as coisas do outro, arrumam encrenca mesmo [...] (E5A).

Esta fala expõe que a escola, entendida como espaço de segurança e propício para o desenvolvimento humano e para a sociabilidade, não consegue com seus muros impedir a proliferação das dificuldades sociais delineadas por uma excitação violenta que passa a compor a maneira como interagimos nas instituições e depois nos locais públicos. Essa lógica não é compartilhada apenas pelos adolescentes, mas também pelas outras pessoas. Os adolescentes enunciam, assim, que a saída possível para estas problemáticas seja delineada a partir da ação dos "governantes" (políticas públicas) e da assunção de responsabilidades individuais (autocuidado) ${ }^{29}$.
Na perspectiva da criminalidade, o "uso de drogas" na adolescência e a influência do contexto particular para seu início ou manutenção é outra dimensão muito destacada por eles. Outros estudos têm apontado que o uso e abuso de drogas têm sido uma das principais causas de transtornos na adolescência, a exemplo dos acidentes, suicídios, homicídios, violência ${ }^{2,16}$. A dependência química tem sido associada ao envolvimento com o crime e a prostituição.

Olha, principalmente o negócio das drogas... As drogas também é muito influenciado... Às vezes a gente escuta assim: droga é pra aliviar, pra esquecer os problemas; eu acho que traz mais problemas [...] (E5B).

Problematizar o uso e o abuso de drogas, e a prevenção destas situações junto aos adolescentes, é um desafio que se tem imposto àqueles que trabalham e buscam a motivação para a atenção e a educação preventiva em saúde. $O$ adolescente precisa discutir as razões da adoção de um comportamento preventivo e aprender a resistir às pressões, por exemplo, para experimentar drogas. Isto só é possível a partir de práticas dialógicas, contextuais e intersetoriais ${ }^{3,16}$.

A exploração sexual de adolescentes e jovens, por sua vez, também se caracteriza como uma cruel expressão da desigualdade e da questão social. No cenário social estudado, a questão da exploração sexual ultrapassa a questão de gênero, quando os sujeitos apontam que este fato se insere no mundo tanto para as meninas quanto para os meninos.

Tem também a prostituição. Os adolescentes não gostam, mas às vezes precisam. A prostituição está caindo muito no mundo dos jovens, tanto pras meninas como pros meninos (E1B).

A exploração sexual de adolescentes compreende o abuso sexual, sendo estes tratados como objeto sexual e mercadoria. Esta prática se constitui em uma forma de coerção e violência a qual pode implicar o trabalho forçado e formas contemporâneas de escravidão. É determinada não apenas pela violência estrutural, que constitui seu pano de fundo, como pela violência social e interpessoal ${ }^{17,20}$. No entanto, pode se constituir em uma opção que sinaliza a procura pela própria sobrevivência ou para satisfação dos seus desejos e afetos, muito relacionados ao consumismo. Este problema também tem impactos diretos sobre a saúde e qualidade de vida, podendo gerar condições de vulnerabilidade individual, social e programática. 


\section{Conclusão}

A busca da identidade e do novo, a curiosidade, a onipotência e a contestação despertam no adolescente uma sensação de invulnerabilidade que associada a pouca experiência de vida e a fatores como falta de informação adequada, dificuldade de "administrar" esperas e adiar desejos, virtualidade do futuro, existência de um sistema educacional pobre e desestimulante para a individualização e capacitação à sociabilidade rica e a carência e baixa qualidade de serviços de saúde voltados para essa faixa etária fazem com que eles se tornem altamente vulneráveis, considerando-se os aspectos individuais, sociais, contextuais, institucionais e programáticos.

Destaca-se que os fatores de vulnerabilidade apontados pelos adolescentes entrevistados foram aqui apresentados de forma distinta, a fim de demonstrar um melhor entendimento. No entanto, constata-se que estes estão imbricados em uma complexa rede de interação e multifatorialidade que tem no conceito de vulnerabilidade sua perspectiva de compreensão.

Apreende-se, assim, o entendimento de uma complexa interação entre a predisposição individual à vulnerabilidade, o contexto e a presença/ ausência de estrutura social, o que vem confirmar a visão de uma adolescência plural, construída na diversidade, não cabendo mais a ideia de pensar as políticas públicas e as ações comunitárias, a partir de uma perspectiva de universalidade do sujeito adolescente, fortalecendo a concepção de vulnerabilidade a partir das lógicas individual, social e programática.

Neste cenário, a grande pergunta para os profissionais que trabalham diretamente com adolescentes é: como fazer com que suas intervenções realmente possam contribuir para que os adolescentes consigam cuidar-se e prevenir-se de situações que os colocam em situação de vulnerabilidade da saúde?

$\mathrm{Na}$ prática, significa que não podemos mais pensar a prevenção ou a atenção a esta faixa etária a partir de um único referencial, de uma ideia de universalidade de sujeito, que não existe. São sujeitos diferentes, diferenças estas construídas no momento histórico e sociocultural de cada um, portanto em constante mudança, que exigem práticas em saúde integrais, contextuais e dialógicas.

Sabemos que o produto final é sempre provisório, não esgota em si mesmo, sendo possível sua ampliação através de novos olhares. Neste sentido, esperamos com este estudo lançar algumas reflexões acerca da percepção dos adolescentes, incentivar novos estudos e colaborar tanto para a melhoria da práxis dos profissionais de enfermagem como para ampliar o saber na área de saúde do adolescente.

\section{Colaboradores}

MAI Silva, FCM Mello, DF Mello, MGC Ferriani, JMC Sampaio e WA Oliveira participaram igualmente em diferentes etapas de elaboração do artigo. 


\section{Referências}

1. Brasil. Ministério da Saúde (MS). Marco legal: saúde, um direito de adolescentes. Brasília: MS; 2007.

2. Jesus FB, Lima FCA, Martins CBG, Matos KF, Souza SPS. Vulnerabilidade na adolescência: a experiência e expressão do adolescente. Rev Gaúcha Enferm 2011; 32(2):359-367.

3. Sánchez AIM, Bertolozzi MR. Pode o conceito de vulnerabilidade apoiar a construção do conhecimento em Saúde Coletiva? Cien Saude Colet 2007; 12(2):256-261.

4. Ayres JRCM, Calazans GJ, Saletti Filho HC, França-Junior I. Riscos, vulnerabilidade e práticas de prevenção e promoção da saúde. In: Campos GWS, Minayo MCS, Akerman M, Drumond Júnior M, Carvalho YM, organizadores. Tratado de saúde coletiva. São Paulo, Rio de Janeiro: Hucitec, Fiocruz; 2006. p. 375-417.

5. Ferreira RA, Ferriani MGC, Mello DF, Carvalho IP, Cano MA, Oliveira LA. Análise espacial da vulnerabilidade social da gravidez na adolescência. Cad Saude Publica 2012; 28(2): 313-323.

6. Cabral FB, Oliveira, DLLC. Vulnerabilidade de puérperas na visão de Equipes de Saúde da Família: ênfase em aspectos geracionais e adolescência. Rev. esc. enferm. USP 2010; 44(2):368-375.

7. Murphy CFB, Pontes F, Stivanin L, Picoli E, Schochat E. Auditory processing in children and adolescents in situations of risk and vulnerability. São Paulo Med. J. 2012; 130(3):151-158.

8. Anjos RHD, Silva JAS, Val LF, Rincon LA, Nichiata LYI. Diferenças entre adolescentes do sexo feminino e masculino na vulnerabilidade individual ao HIV. Rev. esc. enferm. USP 2012; 46(4):829-837.

9. Cedaro JJ, Vilas Boas LMS, Martins RM. Adolescência e sexualidade: um estudo exploratório em uma escola de Porto Velho - RO. Psicol. cienc. prof. 2012; 32(2):320-339.

10. Paiva V, Ayres JRCM, Segurado AC, Lacerda R, Silva NG, Silva MH, Galano E, Gutierrez PL, Marques HHS, Negra MD, França-Júnior I. A sexualidade de adolescentes vivendo com HIV: direitos e desafios para o cuidado. Cien Saude Colet 2011; 16(10):4199-4210.

11. Alves CA, Brandão ER. Vulnerabilidades no uso de métodos contraceptivos entre adolescentes e jovens: interseções entre políticas públicas e atenção à saúde. Cien Saude Colet 2009; 14(2):661-670.

12. Murakami JK, Petrilli Filho JF, Telles Filho PCP. Talking about sexuality, STI and AIDS with poor adolescents. Rev Latino-Am Enfermagem 2007; 15(1): 864-866.

13. Silva KS, Rozenberg R, Bonan C, Chuva VCC, Costa SF, Gomes MASM. Gravidez recorrente na adolescência e vulnerabilidade social no Rio de Janeiro (RJ, Brasil): uma análise de dados do Sistema de Nascidos Vivos. Cien Saude Colet 2011; 16(5):24852493.

14. Carinhanha JI, Penna LHG. Violência vivenciada pelas adolescentes acolhidas em instituição de abrigamento. Texto contexto - enferm 2012; 21(1):68-76.

15. Morais NA, Morais CA, Reis S, Koller SH. Promoção de saúde e adolescência: um exemplo de intervenção com adolescentes em situação de rua. Psicol. Soc. 2010; 22(3):507-518.
16. Silva KL, Dias FLA, Cunha NF, Pinheiro VPNC. Reflexões acerca do abuso de drogas e da violência na adolescência. Esc. Anna Nery 2010; 14(3):605610.

17. Xavier KR, Conchão $S$, Carneiro Junior N. Juventude e resiliência: experiência com jovens em situação de vulnerabilidade. Rev. bras. crescimento desenvolv. hum. 2011; 21(1):140-145.

18. Ruotti C, Massa, VC, Peres MFT. Vulnerabilidade e violência: uma nova concepção de risco para o estudo dos homicídios de jovens. Interface (Botucatu) $2011 ; 15(37): 377-389$.

19. Gontijo D, Medeiros M. Crianças e adolescentes em situação de rua: contribuições para a compreensão dos processos de vulnerabilidade e desfiliação social. Cien Saude Colet 2009; 14(2):467-475.

20. Cocco M, Lopes, MJM. Violência entre jovens: dinâmicas sociais e situações de vulnerabilidade. Rev Gaucha Enferm 2010; 31(1):151-159.

21. Barcelos MRB, Vasconcellos LCF, Cohen, SC. Políticas públicas para adolescentes em territórios vulneráveis. Rev. bras. promoç. Saúde. 2010; 23(3).

22. Minayo MCS. O desafio do conhecimento: pesquisa qualitativa em saúde. 12a Edição. São Paulo: Hucitec; 2010.

23. Minayo MCS. Análise qualitativa: teoria, passos e fidedignidade. Cien Saude Colet 2012; 17(3):621-626.

24. Fontanella BJB, Ricas J, Turato ER. Amostragem por saturação em pesquisas qualitativas em saúde: contribuições teóricas. Cad Saude Publica 2008; 24(1):17-27.

25. Brasil. Ministério da Saúde (MS). Conselho Nacional de Saúde. Resolução no 196 de 10 de outubro de 1996. Diretrizes e Normas Regulamentadoras de Pesquisas Envolvendo Seres Humanos. Diário Oficial da União 1996; 16 out.

26. Dayrell J. A escola "faz" as juventudes? Reflexões em torno da socialização juvenil. Rev. Educação e Sociedade 2007; 28(100):1105-1128.

27. Hoga LAK. Adolescent maternity in a low income community: experiences revealed by oral history. Rev Latino-Am Enfermagem 2008; 16(2):280-286.

28. Ribas RP. A caracterização da pobreza urbana ao longo do tempo: aplicação do modelo idade-período-coorte na estimação das tendências de privações crônica e transitória no Brasil. Rev. Bras. Estud. Popul. 2007; 24(1):139-161.

29. Castro MG, Abramovay M. Quebrando mitos: juventude, participação e políticas. Perfil, percepções e recomendações dos participantes da $1^{\text {a }}$ Conferência Nacional de Políticas Públicas para a Juventude. Brasília: Ritla; 2009.

30. Waiselfisz JJ. Mapa da Violência 2012: A cor dos homicídios no Brasil. Rio de Janeiro, Brasília: Cebela, Flacso, SEPPIR/PR; 2012.

Artigo apresentado em 30/11/2012

Aprovado em 15/01/2013

Versão final apresentada em 21/01/2013 
